\title{
Optimization of an integrated batch production and maintenance scheduling on flow shop with two machines
}

\author{
Zahedi Zahedi $^{a^{*}}$, Ashadi Salim ${ }^{a}$, Rinto Yusriski ${ }^{\mathrm{b}}$ and Haris Haris ${ }^{\mathrm{c}}$
}

${ }^{a}$ Department of Mathematics, School of Computer Science, Binus University, Syahdan Street 9, Jakarta 11480, Indonesia ${ }^{b}$ Department of Industrial Engineering, Faculty of Engineering, Jendral Ahmad Yani University (UNJANI), Gatot Subroto Street, Bandung 40285, Indonesia

${ }^{c}$ Trisakti School of Transportation Management, IPN Kebon Nanas Street, Jakarta 13410, Indonesia

\section{H R O N I C L E A B S T R A C T}

Article history:

Received January 82018

Received in Revised Format

January 102018

Accepted July 102018

Available online

July 102018

Keywords:

Flow shop

Two machines

Batch production

Machine maintenance

\begin{abstract}
This paper discusses an integrated model of batch production and maintenance scheduling on flow shop with two deteriorating machines producing single item to be delivered at a due date. The model describes the trade-off between production and maintenance costs as the production run length increases on two machines. The objective function of the model is to minimize the total cost consisting of in process and completed part inventory costs, setup costs, preventive \& corrective maintenance costs and rework costs on two machines. The step-wise optimization algorithm is developed to solve a mixed integer quadratic programming. Comparison with the practice and the model sensitivity analysis are demonstrated to clarify how the algorithm works.
\end{abstract}

(C) 2019 by the authors; licensee Growing Science, Canada

\section{Introduction}

No coordination between production and maintenance divisions in a manufacturing system may cause delay in delivering the orders to customer. A real example is well described by the following case: Company $\mathrm{Y}$ gets some orders of two stages machinery work product in large quantities from its partner company. The manufacturer processes the orders in batches with constant sizes determined by the production division. Meanwhile, the maintenance division uses corrective maintenance action if a failure of the machine occurs. Late delivery orders to partner company cannot be avoided if machine repair time takes long time or the busy machines are not interupted for maintenance.

Some papers that integrate batch production and maintenance scheduling are: Lee and Rosenblatt (1987), Wang and Sheu (2001), Tseng (1996), Lin and Hou (2005), Ben-Daya and Noman (2006), Chelbi et al. (2008), El-ferik and Ben-Daya (2010), Fitouhi and Nourelfath (2012) and Suliman and Jawad (2012). These papers discuss about integrating batch production scheduling and maintenance scheduling in discrete product type, single item, and single deteriorating machine. The decision of the models is the

* Corresponding author

E-mail: zahedizahedi@binus.ac.id (Z.ZZahedi)

2019 Growing Science Ltd.

doi: $10.5267 /$ j. ijiec.2018.7.001 
size and the number the batches and an optimal maintenance time. The total cost consistes of inventory holding, setup, quality and rework costs.

On the other side, the papers that integrate production scheduling on more than one machine are: Berrichi et al. (2009), Moradi et al. (2011) and Chiu et al. (2018). Berrichi et al. (2009) proposed bi-objective optimization algorithm for job production and machines maintenance scheduling. The bi-objectives of the model are minimization of makespan for production scheduling and minimization of machines unavailability for machines maintenance scheduling. Berrichi et al. (2009) used weight summation algorithm by two objectives to search the best schedule for $n$ jobs on $m$ machines manufacturing system. Moradi et al. (2011) proposed bi-objective optimization method to integrate fixed preventive maintenance scheduling and production scheduling for $n$ jobs processed on flexible job shop. The biobjective of this model is the minimization of the makespan on production scheduling and minimization of the machines unavailability on maintenance scheduling. These papers did not consider due date in their discussion. Chiu et. al. (2018) proposed an alternative fabrication scheme to study the effect of rework and delay on multiple items processed on two machines with multiple due dates.

This paper deals with integrating a model of batch production and maintenance scheduling on a single item processed on flow shop with two machines system. An order has to be delivered at a common due date. The objective function of the model is the minimization of the total cost consisting of setup cost, holding costs of work in process and finished parts, preventive and corrective maintenance costs and rework cost for both machines. Decision variables of the model are the number and schedule of the batches on each machine and the number and schedule of preventive maintenance for both machines.

In order to formulate the integrated batch production and maintenance scheduling model for single item processed on flow shop with two machines, the following notations are used.

\section{Parameters}

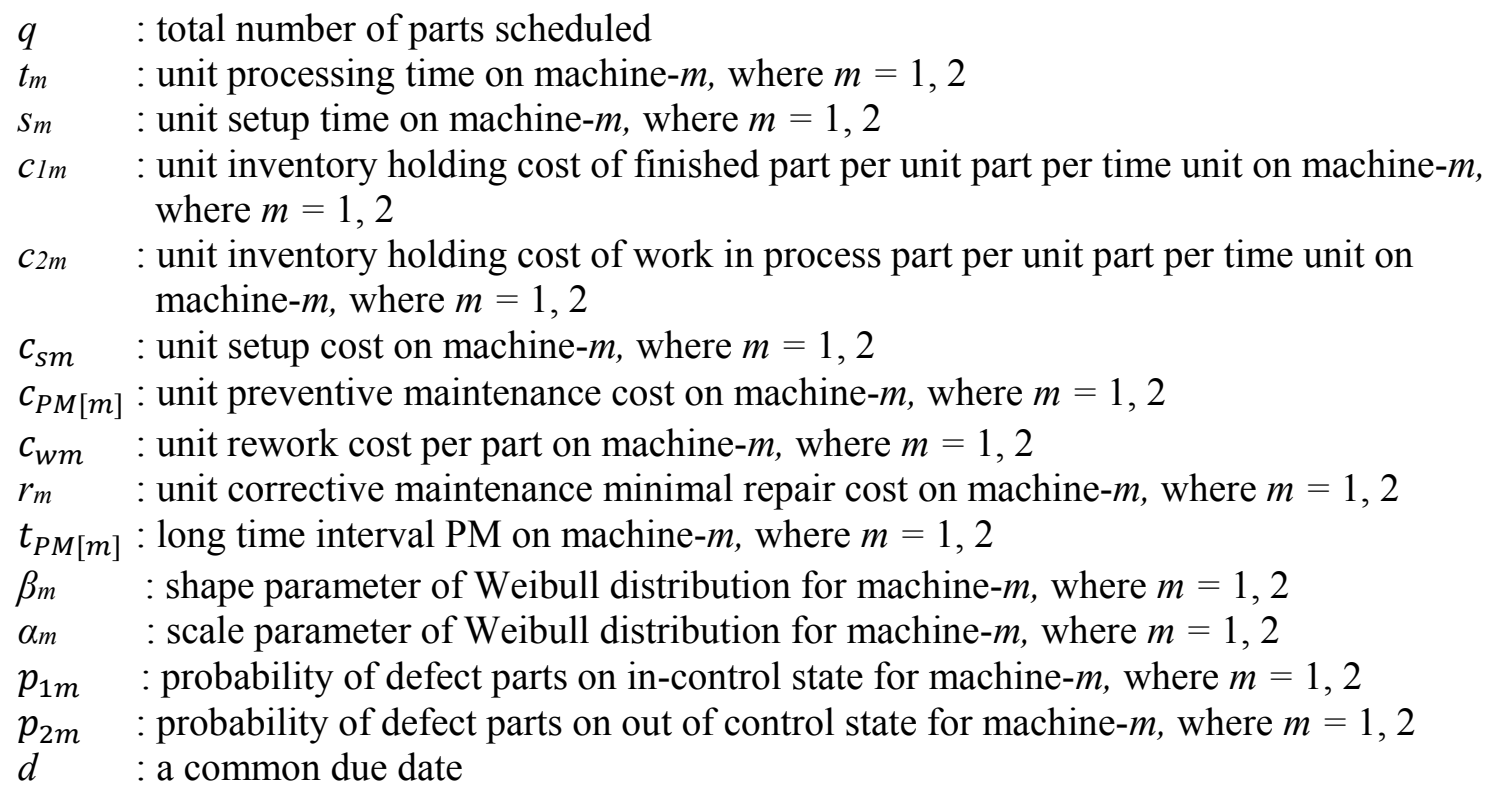

\section{Decision Variables}

$L_{[i k m]}:$ batch scheduled in $i^{\text {th }}$ position in the $k^{\text {th }}$ production run on machine- $m$ (backward), where $i=1,2, \ldots, N_{k m}, k=1,2, \ldots, g_{m}, m=1,2$

$Q_{[i k m]}:$ number of part in batch $L_{[i k m]}$

$N_{k m}:$ maximum number of batch for $k^{\text {th }}$ production run on machine- $m$, where $i=1,2, \ldots, N_{k m}$, $k=1,2, \ldots, g_{m}, m=1,2$

$B_{[i k m]}$ : beginning time of batch $L_{[i k m]}$ 
$C_{[i k m]}:$ completion time of batch $L_{[i k m]}$

$B_{P M_{[k m]}}$ : beginning time of $k^{\text {th }} \mathrm{PM}$ on machine- $m$, where $m=1,2$

$C_{P M_{[k m]}}$ : completion time of $k^{\text {th }} \mathrm{PM}$ on machine- $m$, where $m=1,2$

$n_{C M_{[m]}}$ : number of CM minimal repair as long as a planning horizon on machine- $m$, where

$$
m=1,2
$$

$X_{[i k m]}=\left\{\begin{array}{l}1, \text { if } Q_{[i k m]} \neq 0 \\ 0, \text { if } Q_{[i k m]}=0\end{array}, i=1,2, \ldots, N_{k m}, k=1,2, g_{m}, m=1,2\right.$

$R_{m} \quad$ : total cost of CM minimal repair on machine- $m$, where $m=1,2$

$M_{m} \quad$ : number of non conforming parts on machine- $m$, where $m=1,2$

$R \quad:$ total cost of CM minimal repair on both machines, where $E(R)=E\left(R_{1}\right)+E\left(R_{2}\right)$

$M \quad$ : total number of non conforming parts, where $E(M)=E\left(M_{1}\right)+E\left(M_{2}\right)$

The Objective Function

TC : the total cost consisting of inventory holding cost, setup cost, preventive maintenance and corrective maintenance costs and rework cost.

2. Inventory holding cost formulation for in-process batch and completed batch for single item processed on flow shop with two machines

Fig.1 demonstrates a single item processed on flow shop with two machines in single production run.

First failure estimation The second And so on machine $_{[1]}$

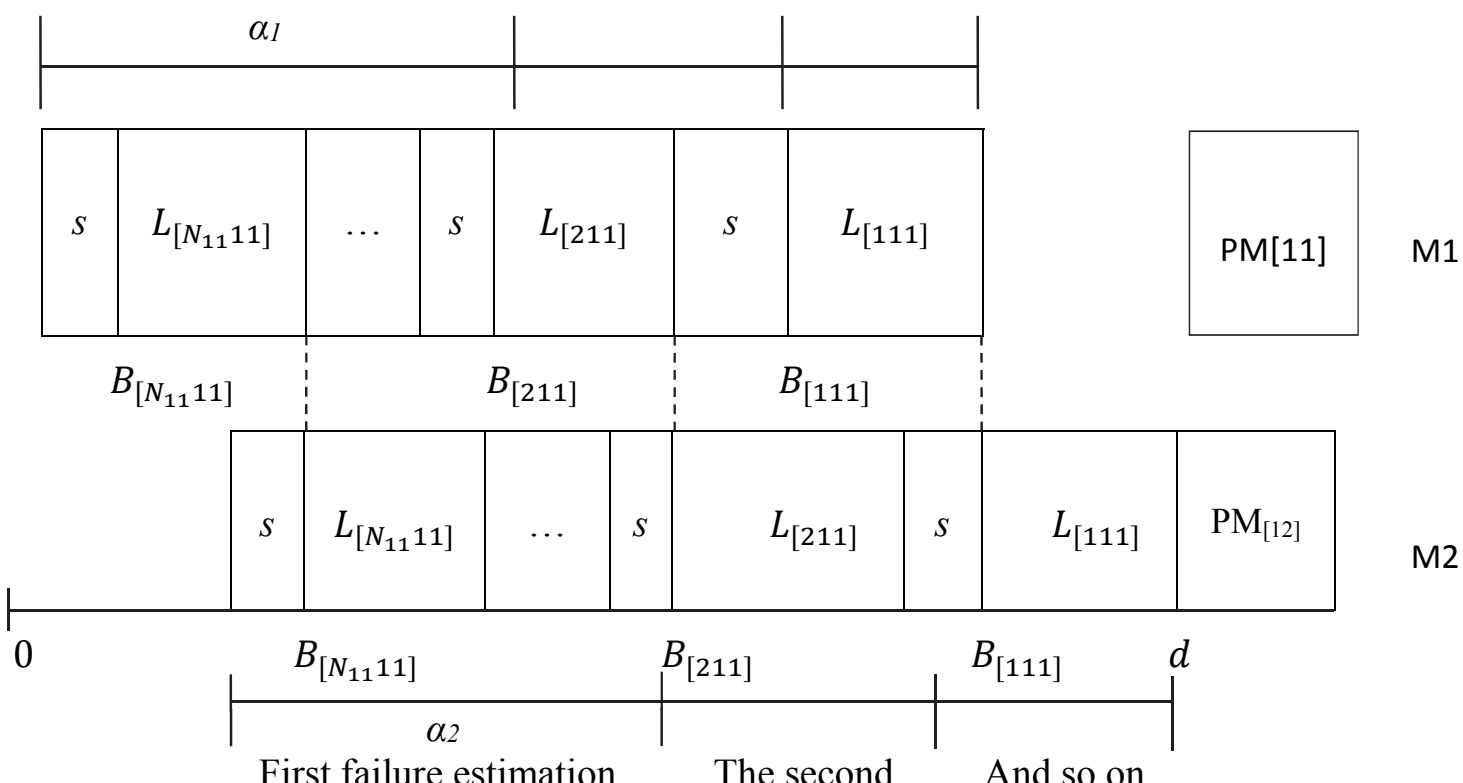

First failure estimation The second And so on machine $_{[2]}$

Fig. 1. Gantt Chart for single item processed on flow shop with two machines

We assume that every completed batch on the first machine will be immediately processed on the second machine, if possible. This assumption will implicate the same number of batch processed on both machines. Let $i^{\text {th }}$ be the batch processed on the first machine with quantity $Q_{[i 11]}$. According to Halim and Ohta (1994), Yusriski et al. (2015), Zahedi et al. (2016) and Prasetyaningsih et al. (2016) then in the process of batch inventory holding cost and completed batch inventory holding cost until the batch is processed on the second machine we have: 
$\frac{c_{11}+c_{21}}{2} t_{1} Q_{[i 11]}^{2}+\frac{c_{21}-c_{11}}{2} t_{1} Q_{[i 11]}+Q_{[i 11]} c_{11}\left(B_{[i 12]}-C_{[i 11]}\right)$.

The $i^{t h}$ completed batch on the first machine is processed on the second machine as soon as possible then the in process batch inventory holding cost on the second machine can be formulated as follows:

$$
\frac{c_{12}+c_{22}}{2} t_{2} Q_{[i 12]}^{2}+\frac{c_{22}-c_{12}}{2} t_{2} Q_{[i 12]} .
$$

The $i^{t h}$ completed batch on the second machine will wait until a common due date $d$, then the completed batch inventory holding cost on the second machine can be formulated as follows:

$$
Q_{[i 12]} c_{12}\left(d-C_{[i 12]}\right) .
$$

In process batch inventory holding cost and completed batch inventory holding cost for $i^{\text {th }}$ batch on both machines can be formulated as Eq. (4).

$$
\begin{aligned}
& \frac{c_{11}+c_{21}}{2} t_{1} Q_{[i 11]}^{2}+\frac{c_{21}-c_{11}}{2} t_{1} Q_{[i 11]}+Q_{[i 11]} c_{11}\left(B_{[i 12]}-C_{[i 11]}\right)+\frac{c_{12}+c_{22}}{2} t_{2} Q_{[i 12]}^{2}+ \\
& \frac{c_{22}-c_{12}}{2} t_{2} Q_{[i 12]}+Q_{[i 12]} c_{12}\left(d-C_{[i 12]}\right) .
\end{aligned}
$$

Further step is to formulate total inventory holding cost for all batches scheduled in single production run (let $\left.N_{1}=N_{11}=N_{12}\right)$ as $T o I C_{[1]}$

$$
\begin{aligned}
& \operatorname{ToIC}_{[1]}=\sum_{i=1}^{N_{1}}\left[\frac{c_{11}+c_{21}}{2} t_{1} Q_{[i 11]}^{2}+\frac{c_{21}-c_{11}}{2} t_{1} Q_{[i 11]}+\frac{c_{12}+c_{22}}{2} t_{2} Q_{[i 12]}^{2}+\right. \\
& \left.\frac{c_{22}-c_{12}}{2} t_{2} Q_{[i 12]}+Q_{[i 12]} c_{12}\left(d-C_{[i 12]}\right)+Q_{[i 11]} c_{11}\left(B_{[i 12]}-C_{[i 11]}\right)\right] .
\end{aligned}
$$

In developing total inventory holding for single item processed on flow shop with two machines, we consider the following:

1. The number of production run on the first and the second machines may be different because both machines have different ROCOF functions.

2. The number of batches on each production run for each machine can be different.

3. Each completed batch on the first machine is processed on the second machine as soon as possible, so that the number of batches in all of production runs for both of machines will be the same.

Assume there are $g_{1}$ production runs on the first machine and $g_{2}$ production runs on the second machine, The total inventory holding cost for all batches is formulated as Eq. (6).

$$
\begin{aligned}
& \text { ToIC } C_{\left[g_{1} g_{2}\right]}=
\end{aligned}
$$

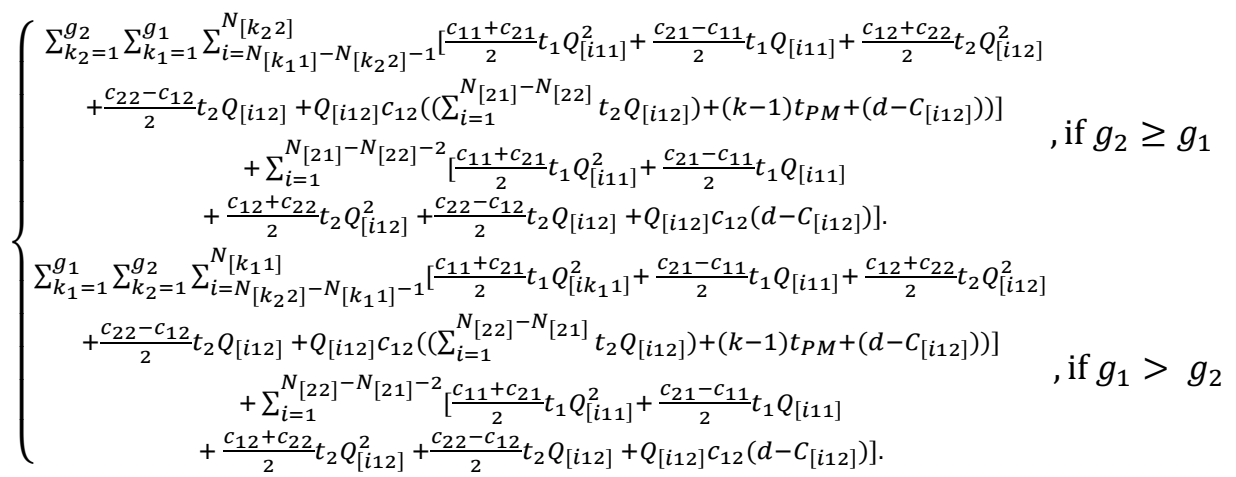




\section{Maintenance policy and states of the machines}

Failure time density function used in this paper is Weibull distribution with scale parameter $\alpha$ and shape parameter $\beta$ forecasted from machine failure data in the shop. The cumulative ROCOF (rate of occurrence of failures) (see Murthy \& Jiang, 2008) or the expected total number of failures in the interval $[0, t)$ is given by the function

$$
\Lambda(t)=\left(\frac{t}{\alpha}\right)^{\beta}
$$

Cumulative ROCOF function can be used to estimate the time interval between machine failure times. In this paper, we assume that the two machines are as good as a brand new machine at time zero and the elapsed time the machines is deteriorated follows the Weibull distribution. The machines is operated until the first failure time based on ROCOF function and we assume that the machines are in in-control state. After the first failure time with no preventive maintenance action, the machines will be in out of control state. For other preventive maintenance cost policy see Mo et. al. (2017).

\section{Estimation of non-conforming parts}

Suppose the probability of non conforming parts in in-control state is $p_{1 m}, m=1,2$, and the probability of non conforming parts in out of control state is $p_{2 m}, m=1,2$, where $p_{2 m}>p_{1 m}$. In the same way with single machine case (see Zahedi et al., 2016), let the number of non-conforming parts will be always in the last production run processed in the first production run scheduled as $M_{\mathrm{m}} . M_{\mathrm{m}}$ can be formulated as

$$
\begin{aligned}
& M_{m}=\sum_{k=2}^{g_{m}} p_{1 m} x \text { number of parts processed in interval }\left[B_{\left[N_{k} k m\right]}-s, C_{[1 \mathrm{~km}]}\right] \\
& +p_{1 m} x \text { number of parts processed in interval }\left[B_{\left[N_{1} 1 m\right]}-s, B_{\left[N_{1} 1 m\right]}-s+\alpha_{m}\right] \\
& +p_{2 m} x \text { number of parts processed in interval }\left[B_{\left[N_{1} 1 m\right]}-s+\alpha_{m}, C_{[11 \mathrm{~m}]}\right] \text {, where } m=1,2 .
\end{aligned}
$$

Furthermore, we can calculate the expected number of non conforming parts as

$$
E\left(M_{m}\right)=M_{m} \text {, where } m=1,2 \text {. }
$$

Therefore, the expectation of the rework cost can be formulated as

$$
E(W)=c_{w 1} E\left(M_{1}\right)+c_{w 2} E\left(M_{2}\right)
$$

The possible number of CM minimal repair (only in the first production run from due date direction) based on the ROCOF function for each machine can be formulated as

$$
n_{C M_{[m]}}=\left\{\left\{\frac{d-B_{\left[N_{1 m]}-s+\alpha_{m}\right)}}{\alpha_{m}}\right\}^{\beta_{m}}\right] \text {, where } m=1,2 .
$$

Furthermore, the expectation of $\mathrm{CM}$ minimum repair cost as long as a the planning horizon can be formulated as follows,

$$
E(R)=\sum_{m=1}^{2} c_{r m} n_{C M_{[m]}},
$$

where $c_{r m}$ is unit CM minimal repair cost on machine- $m$, where $m=1,2$.

\section{Model construction and algorithm}

\subsection{Model construction}

We adopt some assumptions in formulating the model as follow:

1. The integrating model for single item is processed on flow shop with two machines, 
2. Setup time does not depend on the number of parts in batches for both machines,

3. For both machines, the batch number and preventive maintenance number are counted from due date direction (backward approach),

4. The same load force for machine in setup time and in processing time for each machine is considered, 5. The machine cannot be interrupted as long as the production runs for both machines are completed,

6. Batch size values are in real positive.

Using the defined notations and based on the assumptions, the integrated batch production scheduling and maintenance scheduling to minimize production and maintenance costs for single item processed on flow shop with two deteriorating machines with due date constraint will have objective function and system constraints as follow.

The objective function of the model is the minimization of total cost consisting the total inventory costs, total preventive cost, total setup cost, total corrective maintenance cost and rework cost. The objective function can be written as

$$
\mathrm{TC}=\operatorname{ToI}_{\left[g_{1} g_{2}\right]}+\sum_{m=1}^{2} g_{m} c_{P M[m]}+\sum_{m=1}^{2} \sum_{k=1}^{g_{m}} c_{s m} N_{k m}+E(R)+E(W) .
$$

The total number of parts in all batches on each machine must be equal to the total number of parts that will be scheduled. The constraint can be written as two constraints as follow,

$$
\begin{aligned}
& \sum_{k=1}^{g_{1}} \sum_{i}^{N_{k 1}} Q_{i k 1}=q, \\
& \sum_{k=1}^{g_{2}} \sum_{i}^{N_{k 2}} Q_{i k 2}=q .
\end{aligned}
$$

The beginning time of a batch on the first machine must be less than or equal to the beginning time of the batch on the second machine. It can be written as,

$$
B_{\left[i_{k 1}\right]}+t_{1} Q_{\left[i_{k 1}\right]} \leq B_{\left[i_{k 2}\right]}, i_{\mathrm{k} 1}=1,2, \ldots, N_{k 1}, i_{k 2}=1,2, \ldots, N_{k 2} .
$$

The completion time of the first batch scheduled or the last batch processed (backward approach) for the first production run on the second machine must be equal to the due date. i.e.

$$
B_{[112]}+t_{2} Q_{112}=d
$$

The completion time of the second batch and the next batches for the first production run on the second machine must be less than or equal to the due date and it can be written as follows,

$$
B_{[i 12]}+t_{2} Q_{[i 12]}+\sum_{l=1}^{i 12-1}\left(t_{2} Q_{[l]}+s\right) \leq d, i_{12}=2,3, \ldots, N_{12}
$$

The completion time of the batches for the second production run and the next runs on the second machine must be less than or equal to the due date and is written as follows,

$$
B_{\left[i_{k 2} k 2\right]}+t_{2} Q_{\left[i_{k 2} k 2\right]}+\sum_{l=1}^{i_{k 2}-1}\left(t_{2} Q_{[l]}+s\right) \leq d, i_{k 2}=1,2, \ldots, N_{k 2}, k=2,3, \ldots, g_{2} .
$$

The number of batches for both machines must be the same. It can be written as follows,

$$
\sum_{k=1}^{g_{1}} N_{k 1}=\sum_{k=1}^{g_{2}} N_{k 2}
$$

The length of the first production run on the first machine and all production runs on the second machine must be less than or equal to the due date and can be written as follows, 


$$
\left(s_{1}+t_{1} Q_{\left[N_{11} 11\right]}\right)+\sum_{i=1}^{N_{12}}\left(t_{2} Q_{[i 12]}+s X_{[i 12]}\right) \leq d .
$$

The length of each production run must be less than or equal to the first failure of the machine and can be written as follows,

$$
\sum_{i=1}^{N_{k m}}\left(t_{i} Q_{\left[i_{k m}\right]}+s X_{\left[i_{k m}\right]}\right) \leq \alpha_{m}, k=2,3, \ldots, g_{m}, m=1,2
$$

The maximum possibility number of batch for the system with two machines can be written as follows,

$$
N=\left[\frac{d-\left[\frac{d}{\min \left\{\alpha_{1}, \alpha_{2}\right\}}\right] \cdot \operatorname{maks}\left\{t_{P M[1]}, t_{P M[2]}\right\}-q \cdot \operatorname{maks}\left\{t_{1}, t_{2}\right\}}{\min \left\{s_{1}, s_{2}\right\}}\right] \text {. }
$$

The maximum possibility number of production run for both machines can be written as follows,

$$
g_{m}=\left\lfloor\frac{d}{\alpha_{m}}\right\rfloor, m=1,2 \text {. }
$$

The expectation number of non conforming parts for both machines and the total rework cost for nonconforming parts can be written as the following two constraints,

$$
\begin{aligned}
& E\left(M_{m}\right)=\sum_{k=2}^{g_{m}} p_{1 m} x \text { number of parts processed in interval }\left[B_{\left[N_{k} k m\right]}-s, C_{[1 \mathrm{~km}]}\right] \\
& \quad+p_{1 m} \mathrm{x} \text { number of parts processed in interval }\left[B_{\left[N_{1} 1 m\right]}-s, B_{\left[N_{1} 1 m\right]}-s+\alpha_{m}\right] \\
& \quad+p_{2 m} \mathrm{x} \text { number of parts processed in interval }\left[B_{\left[N_{1} 1 m\right]}-s+\alpha_{m}, C_{[11 m]}\right], m=1,2 \\
& E(W)=c_{w 1} E\left(M_{1}\right)+c_{w 2} E\left(M_{2}\right) .
\end{aligned}
$$

The expectation number of corrective maintenance (minimal repair) with cumulative Weibull ROCOF for both machines and the total corrective maintenance cost can be written respectively as two constraints as follow,

$$
\begin{aligned}
& n_{C M_{[m]}}=\left\lfloor\left\{\frac{\left.d-B_{\left[N_{1 m} 1 m\right]}-s+\alpha_{m}\right)}{\alpha_{m}}\right\}^{\beta_{m}}\right\rfloor, m=1,2 \\
& E(R)=\sum_{m=1}^{2} c_{r m} n_{C M_{[m]} .}
\end{aligned}
$$

A set of constraints for the beginning and the next PM times for both of machines can be written as follows,

$$
\begin{aligned}
& C_{[111]}<B_{P M_{[11]}}, \\
& C_{[1 k 1]} \leq B_{P M_{[k 1]}}, k=2,3, \ldots, g_{1} \\
& C_{[1 k 2]} \leq B_{P M_{[k 2]}}, k=1,2,3, \ldots, g_{2}
\end{aligned}
$$

The completion time of a batch must be less than or equal to the beginning time of the previous batch for both machines and it can be written as follows,

$$
C_{[i k m]} \leq B_{[(i-1) k m]}, i=2,3, \ldots, N_{k m}, k=1,2,3, \ldots, g_{m}, m=1,2
$$


The completion time of all batches scheduled for both machines can be written as follows,

$$
C_{[i k m]}=B_{[i k m]}+t_{m} Q_{[i k m]}, i=2,3, \ldots, N_{k m}, k=1,2,3, \ldots, g_{m}, m=1,2 .
$$

Non-negativity of batch size for both machines can be written as follow,

$$
Q_{[i k m]} \geq 0, i=1,2, \ldots, N_{k m}, k=1,2, \ldots, g_{m}, m=1,2
$$

The size of a batch must be less than or equal to all parts that will be scheduled for both machines and it can be written as follow,

$$
Q_{[i k m]} \leq X_{[i k m]} q, i=1,2, \ldots, N_{k m}, k=1,2, \ldots, g_{m}, m=1,2
$$

The number of batches in each production run for both machines must be one batch or more and it can be written as follow,

$$
N_{k m} \geq 1, k=1,2, \ldots, g_{m}, m=1,2 .
$$

The last constraint is associated with binary variables in batch process. A batch will have $X_{[i \mathrm{~km}]}=1$ for non-empty batch and $X_{[i k m]}=0$ for empty batches for both of machines. Thus,

$$
X_{[i k m]}=\left\{\begin{array}{c}
1, \text { if } Q_{[i k m]} \neq 0 \\
0, \text { if } Q_{[i k m]}=0
\end{array}, i=1,2, \ldots, N_{k m}, k=1,2, \ldots, g_{m}, m=1,2\right.
$$

The model of integrated batch production and maintenance scheduling to minimize production and maintenance costs for single item processed on flow shop with two deteriorating machines with due date constraint (Model [SITM]) can be rewritten in simple form as follow,

Model [SITM]

$\min$ eq. (13)

subject to

eqs. $(14-37)$.

\subsection{Algorithm}

The Model [SITM] was a mix integer quadratic programming, with some integer and binary variables, so that analytic search solution could not be easily used for the model (Winston, 2004).

Algorithm for searching solution called Algorithm [SITM]. The algorithm starts with problem feasibility to the model, where the sum of processing time for single batch and single setup time for both machines will not exceed the due date $d$. The next step is to estimate the maximum number of production run and the maximum number of batches. The initial total cost is calculated from single batch for both machines. We perform batch process by increasing the number of batch on single production run for both machines until we reach the total allowable cost or maximum number of batch. Batching processes are performed for all possible combination of the number of production run for both machines. We collect the set of the best total cost for each possible combination number of production run for both machines. The algorithm solution minimizes the total cost for each possible combination of production run for both machines. Finally, we write the solution algorithm and all decision variables. The complete Algorithm [SITM] is as follows:

\section{Algorithm [SITM]}

Step 1. Compute the expected first failure times based on cumulative Weibull ROCOF functions 
for the first and the second machines as $\alpha_{1}$ and $\alpha_{2}$ respectively. Go to Step-2.

Step-2. A problem is assumed feasible if and only if the total processing time for single batch with single setup for both machines would not exceed the due date $d$, otherwise the problem is not feasible for a model or if $B_{[111]}-s_{1^{+}} t_{2} Q_{[112]} \leq d$ then the problem is feasible, go to Step- 3 . Otherwise, the problem is not feasible, STOP.

Step-3. Compute $g_{m}$ by Eq. (24) and Set $N_{k m}=[N]$, with $N$ calculated by Eq. (23), where $k=1,2, \ldots, g_{m}, m=1,2$. Go to Step-4.

Step-4. For $R=\left\{k=\left(k_{1}, k_{2}\right) \mid k_{1}=1,2, \ldots, g_{1}, k_{2}=1,2, \ldots, g_{2}\right\}$. Go to Step-5.

Step-5. Set $R=(1,1)$. Go to Step-6.

Step-6. Set $k=R$. Go to Step-7.

Step-7. Substitute the values of $g_{m}, N_{k m}, q, p_{m}, t_{m}, S_{m}, d, t_{P M[m]}, k=(1,1), m=1,2$, into the Model [SITM] and Set $X_{[i k m]}=1$ for $i_{k m}=1, k=(1,1), m=1,2$ and $X_{[i k m]}=0$ otherwise. Go to Step-8.

Step-8. Solve Model [SITM] by relaxing Eqs. (25-28). Compute the estimated total rework cost by Eq. (26) and the estimated CM minimal repair cost by Eq. (28) obtained from the schedule. Then compute the total cost $T C$, write $T C_{[111]}=T C$. Go to Step-9

Step-9. Set $\mathrm{k}=\left(k_{1}, k_{2}\right)=(1,1)$. Go to Step-10.

Step-10. Set $i_{k m}=2$. Go to Step-11.

Step-11. Set $X_{[j k m]}=1$ for $j=1,2, \ldots, i_{k m}$ and $X_{[j k m]}=0$ otherwise. Go to Step-12.

Step-12. Solve Model [SITM] by relaxing Eqs. (25-28). Compute the estimated total rework cost by Eq. (26) and the estimated CM minimal repair cost by Eq. (28) obtained from the schedule. Then compute the total cost $T C$, write $T C_{[i k m]}=T C$. Go to Step-13.

Step-13. Evaluate whether $T C_{[\mathrm{i} k m]}<T C_{[(i-1) \mathrm{km}]}$,

- if $T C_{[i k m]}<T C_{[(i-1) k m]}$, evaluate whether $i_{k m}=N$, - if $i_{k m}=N$, go to Step-14,

- otherwise, set $i_{k m}=i_{k m}+1$, go back to Step-11,

- otherwise, set $T C^{*}=T C_{[(i-1) \mathrm{km}]}$ and write all of $T C^{*}$-related decision variables, go to Step -15 .

Step-14. Set $T C^{*}=T C_{[i k m]}$ and write all of $T C^{*}$-related decision variables, go to Step-28

Step-15. Evaluate whether $k=\left(g_{1}, g_{2}\right)$,

- if $k=\left(g_{1}, g_{2}\right)$, go to Step-28.

- otherwise, go to Step-16.

Step-16. Set $\mathrm{k}=\left(k_{1}+1, k_{2}\right)$, go to Step-17.

Step-17. Set $i_{k m}=1$, Set $X_{[i k m]}=1$ for $i_{k m}=1$ and $X_{[i k m]}=0$ otherwise. Solve Model [SITM] by relaxing Eqs. (25-28). Compute the estimated total rework cost by Eq. (26) and the eestimated CM minimal repair cost by Eq. (28) obtained from the schedule. Then compute the total cost $T C$, write $T C_{[i k m]}=T C^{*}$. Go to Step- 18 .

Step-18. Set $i_{k m}=2$, go to Step-19.

Step-19. Set $X_{[j k m]}=1$ for $j=1,2, \ldots, i_{k m}$ and $X_{[j k m]}=0$ otherwise. Go to Step-20.

Step-20. Solve Model [SITM] by relaxing Eqs. (25-28). Compute the estimated total rework cost by Eq. (26) and the estimated CM minimal repair cost by Eq. (28) obtained from the schedule. Then compute the total cost $T C$, write $T C_{[i k m]}=T C$. Go to Step-20.

Step-21. Evaluate whether $T C_{[i k m]}<T C^{*}$,

- if $T C_{[i k m]}<T C^{*}$, set $T C^{*}=T C_{[i k m]}$ and set $i_{k m}=i_{k m}+1$, go back to Step-19.

- otherwise, evaluate whether $k=\left(g_{1}, k_{2}\right)$,

- if $k=\left(g_{1}, k_{2}\right)$. Go to Step-28 and go to Step-22.

- otherwise, set $k_{1}=k_{1}+1$, go back to Step-17.

Step-22. Set $\mathrm{k}=\left(k_{1}, k_{2}+1\right)$, go to Step-23.

Step-23. Set $i_{k m}=1$.Solve Model [SITM] by relaxing Eqs. (25-28). Compute the estimated total rework cost by Eq. (26) and the estimated CM minimal repair cost by Eq. (28) obtained from the schedule. Then compute the total cost $T C$, write $T C_{[i k m]}=T C^{*}$. Go 
to Step-18.

Step-24. Set $i_{k m}=2$, go to Step-25.

Step-25. Set $X_{[j k m]}=1$ for $j=1,2, \ldots, i_{k m}$ and $X_{[j k m]}=0$ otherwise. Go to Step-26.

Step-26. Solve Model [SITM] by relaxing Eqs. (25-28). Compute the estimated total

rework cost by Eq. (26) and the estimated CM minimal repair cost by Eq. (28)

obtained from the schedule. Then compute the total cost $T C$, write $T C_{[i k m]}=T C^{*}$. Go

to Step-25.

Step-27. Evaluate whether $T C_{[i k m]}<T C^{*}$,

- if $T C_{[i k m]}<T C^{*}$, set $T C_{[i k m]}=T C^{*}$, Set $i_{k m}=i_{k m}+1$, go back to Step-25.

- otherwise, evaluate whether $k=\left(k_{1}, g_{2}\right)$,

- if $k=\left(k_{1}, g_{2}\right)$, set $T C_{[i k m]}=T C^{*}$. Go to Step-28.

- otherwise, set $k_{2}=k_{2}+1$, go back to Step-15.

Step-28. Write $T C_{[\text {不 }}=T C^{*}, R=\left\{k=\left(k_{1}, k_{2}\right) \mid k_{1}=1,2, \ldots, g_{1}, k_{2}=1,2, \ldots, g_{2}\right\}$. Go to Step-29.

Step-29. Write $\left\{T C_{[R]}, R=\left\{k=\left(k_{1}, k_{2}\right) \mid k_{1}=1,2, \ldots g_{1}, k_{2}=1,2, \ldots, g_{2}\right\}\right\}$. Go to Step-30.

Step-30. The best solution is minimization $\left\{T C_{[\text {R] }}, R=\left\{k=\left(k_{1}, k_{2}\right) \mid k_{1}=1,2, \ldots, g_{1}\right.\right.$,

$\left.k_{2}=1,2, \ldots, g_{2}\right\}$. Go to Step-31.

Step-31. Write all of decision variables. STOP.

\subsection{Numerical experience}

To clarify how the proposed algorithm work, the following example is given. Consider a problem of single item processed on flow shop with two machines with the following parameters:

The total number of parts scheduled is $q=200$ unit parts, the unit processing time on the first and the second machines are $t_{1}=30$ and $t_{2}=20$ in minutes, respectively, the unit setup time on the first and the second machines are $s_{1}=20$ and $s_{2}=10$ in minutes, respectively, the unit inventory holding cost for finished part on the first and the second machines are $c_{11}=0.4$ and $c_{12}=0.4$ in US\$ per unit part per minute, respectively, the unit inventory holding cost for in process part on the first and the second machines are $c_{21}=0.2$ and $c_{22}=0.2$ in US $\$$ per unit part per minute, respectively, the unit setup cost on the first and the second machines are $c_{s 1}=5$ and $c_{s 2}=3$ in US\$, respectively, the unit preventive maintenance cost on the first and the second machines are $c_{P M[1]}=50$ and $c_{P M[2]}=40$ in US\$, respectively, the unit rework cost for non conforming part on the first and the second machines are $c_{w 1}=60$ and $c_{w 2}$ $=50$ in US\$, respectively, the unit corrective maintenance cost for the first and the second machines are $c_{r 1}=200$ and $c_{r 2}=160$ in US\$, respectively, the length of preventive maintenance action (in constant assumption) for the first and the second machines are $t_{P M[1]}=120$ and $t_{P M[2]}=180$ in minutes, respectively, the shape parameter of Weibull distributions for the first and the second machines are $\beta_{1}=$ 1.14 and $\beta_{2}=1.62$, respectively, the scale parameters are $\alpha_{1}=4,224.00$ and $\alpha_{2}=2,976.00$ in minutes respectively, the probability of defect part for in control state on the first and the second machines are $p_{11}=p_{12}=0$, respectively, the probability of defect part for out of control state are $p_{21}=0.1$ and $p_{22}=0.2$ respectively and a common due date is $d=15,000$.

The computational steps to solve the problem with Algorithm [SITM] are the followings,

Step-1 to Step-8 of Algorithm [SITM] yield the maximum number of production run for the first and the second machines are $g_{1}=3$ and $g_{2}=5$, respectively. The initial solution for the problem is shown as Gantt-Chart in Fig. 2. Expected number of non conforming parts for the first and the second machines are $M_{1}=(6,020-4,224) / 30=59.87$ and $M_{2}=(4010-2976) / 20=51.70$, respectively.

Expected number of corrective maintenance minimal repair for the first and the second machines are $n_{C M[1]}=1$ and $n_{C M[2]}=1$, respectively.

Expected total cost for the first iteration is $T C=599,098.00+(59.87 \times 60)+(51.70 \times 50)+(1 \times 200)+$ $(1 \times 160)=605,635.2$. The characteristic solution for the first iteration is global optimum.

Step-9 to Step-30 yield the best total cost based on Algorithm [SITM] as Table 1. 


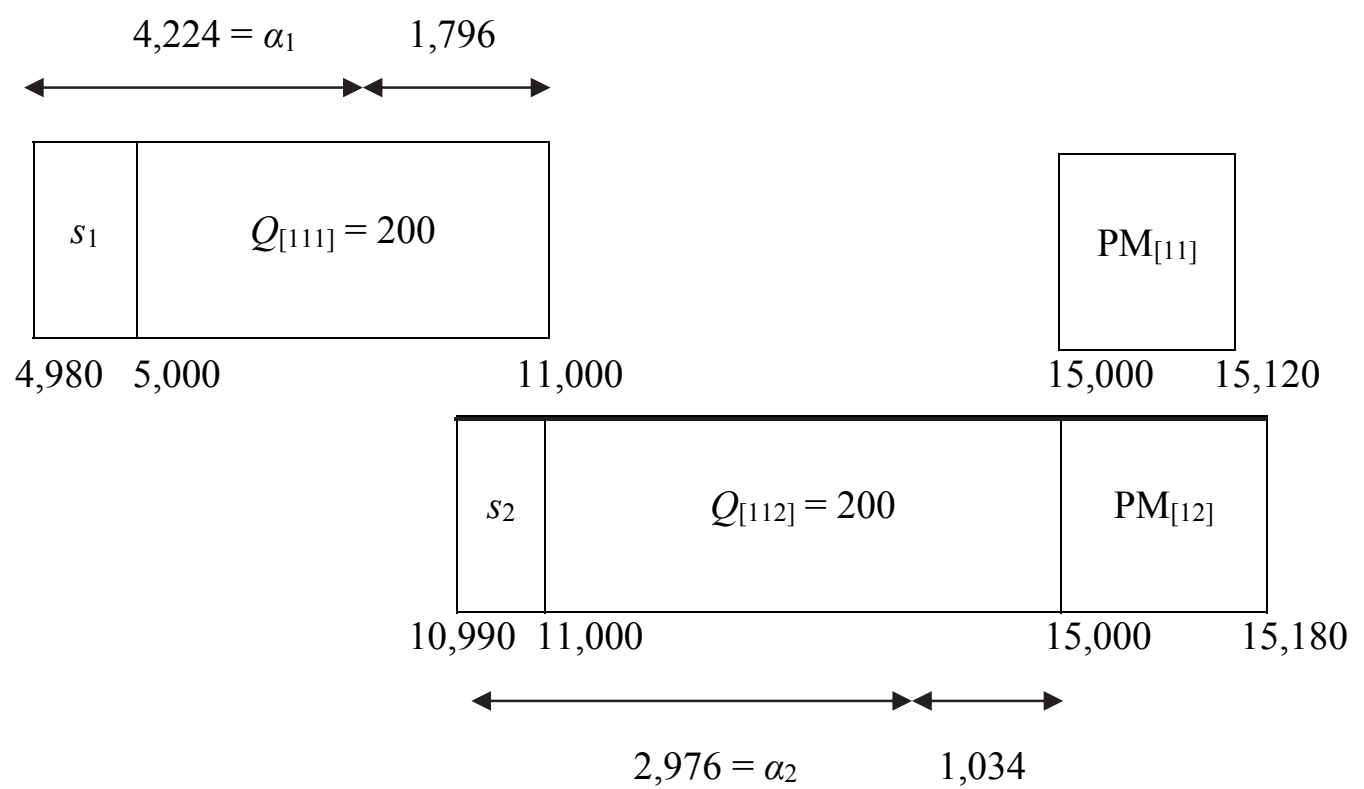

Table 1

Fig. 2. Gantt-Chart for the first iteration with single batch for both of machines

The best solution based on Algorithm [SITM]

\begin{tabular}{|c|c|c|c|c|c|c|c|c|}
\hline \multicolumn{4}{|c|}{ Number of batch } & \multicolumn{2}{|c|}{$\begin{array}{l}\text { Number of non confor } \\
\text { ming part } M_{[m]}\end{array}$} & \multicolumn{2}{|c|}{$\begin{array}{c}\text { Number of CM } \\
n_{C M[m]}\end{array}$} & \multirow[b]{3}{*}{$T C^{*}$} \\
\hline \multicolumn{2}{|c|}{$M_{[l]}$} & \multicolumn{2}{|c|}{$M_{[2]}$} & & & & & \\
\hline $\operatorname{Run}_{[l]}$ & $\operatorname{Run}_{[2]}$ & $\operatorname{Run}_{[1]}$ & $\operatorname{Run}_{[2]}$ & $M_{[l]}$ & $M_{[2]}$ & $M_{[l]}$ & $M_{[2]}$ & \\
\hline 2 & 1 & 3 & 0 & 0 & 52.20 & 0 & 1 & $262,471.90$ \\
\hline
\end{tabular}

Step-31 yields all decision variables is shown as Fig. (3).

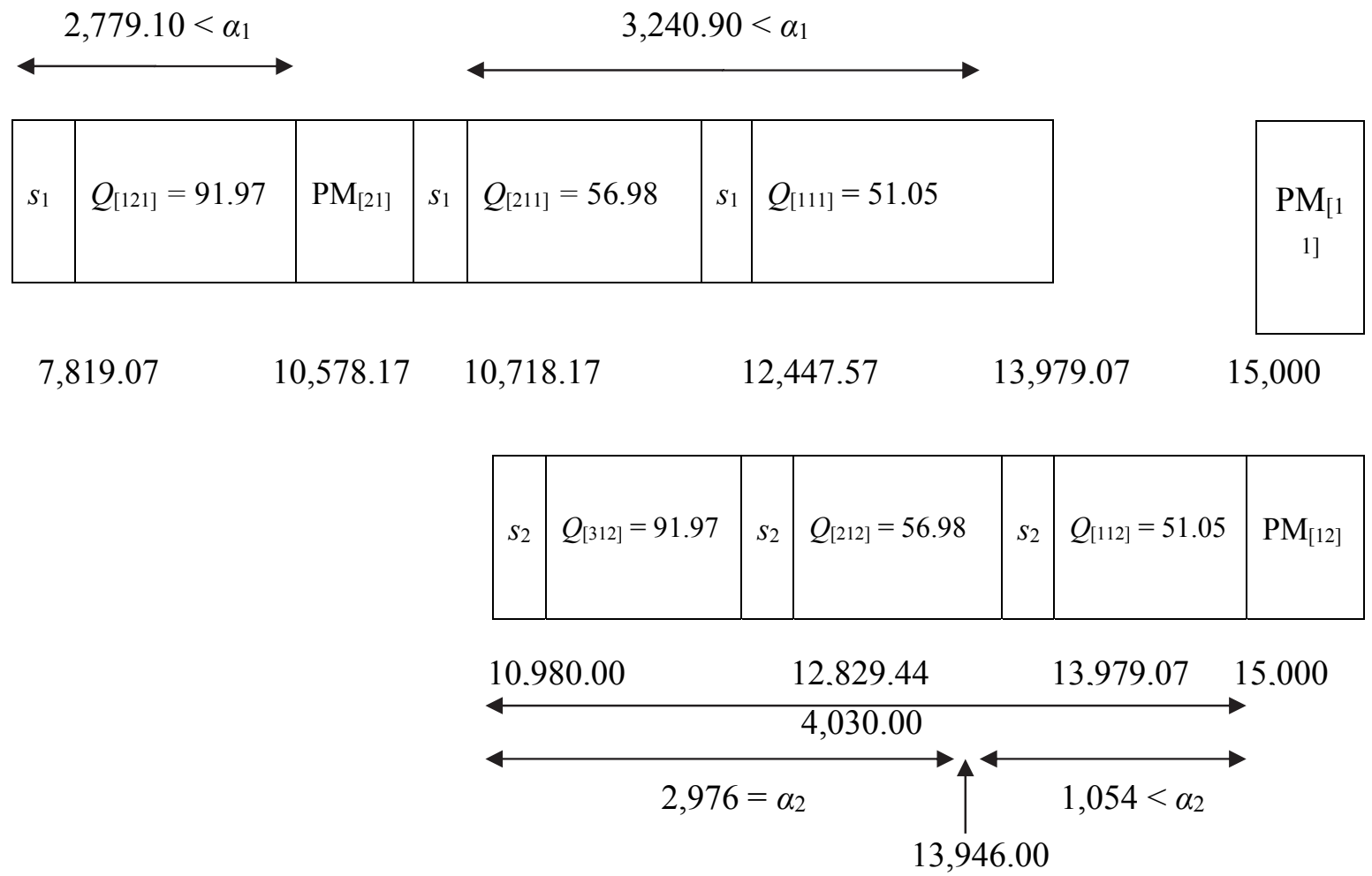

Fig. 3. Gantt-Chart for the best solution of Algorithm [SITM] 


\subsection{A Comparison between model solution and the practice}

Company Y processes an order with constant batch size for every batch and machine maintenance is performed only when failures of the two machines occur (reactive maintenance). If the example case is scheduled with constant batch then 200 parts will be divided into 10 batches, each batch consist of 20 parts. The 10 batches are inserted into the Model [SITM] then the total cost for the constant batch size is US\$ 294,957.10 (see Table 2). While the method developed yields the total cost of US\$262.471,90. The method developed in this paper provides the cost efficiency of at least $12.4 \%$. If machine maintenance time takes long time for maintenance actions because of machine down then it will become the additional opportunity loss for the manufacturer.

Table 2

The best solution based on Algorithm [SITM] for constant batch

\begin{tabular}{|c|c|c|c|c|c|c|c|c|}
\hline \multicolumn{4}{|c|}{ Number of batch } & \multicolumn{2}{|c|}{$\begin{array}{l}\text { Number of non conforming part } \\
\qquad M_{[\mathrm{m}]}\end{array}$} & \multicolumn{2}{|c|}{$\begin{array}{c}\text { Number of CM } \\
n_{C M[m]}\end{array}$} & \multirow[b]{3}{*}{$T C^{*}$} \\
\hline \multicolumn{2}{|c|}{$M_{[1]}$} & \multicolumn{2}{|c|}{$M_{[2]}$} & \multirow[b]{2}{*}{$M_{[l]}$} & \multirow[b]{2}{*}{$M_{[2]}$} & \multirow[b]{2}{*}{$M_{[l]}$} & \multirow[b]{2}{*}{$M_{[2]}$} & \\
\hline $\operatorname{Run}_{[1]}$ & $\operatorname{Run}_{[2]}$ & $\operatorname{Run}[1]$ & $\operatorname{Run}_{[2]}$ & & & & & \\
\hline 6 & 4 & 10 & 0 & 0 & 64.27 & 0 & 1 & $294,957.10$ \\
\hline
\end{tabular}

\subsection{Sensitivity analysis}

Sensitivity analysis of important parameters of the Model [SITM] is shown in Table 3. Table 3 shows the increasing of completed parts inventory holding cost for both machines $\left(c_{1 \mathrm{~m}}\right)$ decrease the number of batches and the total cost. The increase in the process inventory holding cost $\left(c_{2 m}\right)$ will increase the number of batches in the best total cost.

Table 3

Parameter sensitivity analysis for Model [SITM]

\begin{tabular}{|c|c|c|c|c|c|c|c|c|c|c|c|c|}
\hline \multicolumn{2}{|c|}{$c_{1 m}$} & \multicolumn{2}{|c|}{$c_{2 m}$} & \multicolumn{2}{|c|}{$\begin{array}{l}\text { Number of batch } \\
\qquad M_{[1]}\end{array}$} & \multicolumn{2}{|c|}{$\begin{array}{l}\text { Number of batch } \\
\qquad M_{[2]} \\
\end{array}$} & \multicolumn{2}{|c|}{$\begin{array}{l}\text { Number of non } \\
\text { conforming parts }\end{array}$} & \multicolumn{2}{|c|}{ Number of $C M$} & \multirow[t]{2}{*}{$T C$} \\
\hline$c_{11}$ & $c_{12}$ & $c_{21}$ & $c_{22}$ & run $_{1}$ & run $_{2}$ & run $_{1}$ & $\operatorname{run}_{2}$ & $M_{[1]}$ & $M_{[2]}$ & $M_{[1]}$ & $M_{[2]}$ & \\
\hline 0.4 & 0.4 & 0.2 & 0.2 & 2 & 1 & 3 & 0 & 0 & 52.2 & 0 & 1 & $262.471,9$ \\
\hline 0.8 & 0.8 & 0.2 & 0.2 & 2 & 1 & 3 & 0 & 0 & 52.2 & 0 & 1 & $447.971,7$ \\
\hline 0.16 & 0.16 & 0.2 & 0.2 & 2 & 0 & 2 & 0 & 60.5 & 52.2 & 1 & 1 & $628.306,0$ \\
\hline 0.20 & 0.20 & 0.2 & 0.2 & 2 & 0 & 2 & 0 & 60.5 & 52.2 & 1 & 1 & $810.879,6$ \\
\hline \multicolumn{13}{|c|}{4} \\
\hline 0.4 & 0.4 & 0.2 & 0.2 & 2 & 1 & 3 & 0 & 0 & 52.2 & 0 & 1 & $262.471,9$ \\
\hline 0.4 & 0.4 & 0.4 & 0.4 & 2 & 2 & 3 & 1 & 0 & 0 & 1 & 1 & $330.959,3$ \\
\hline 0.4 & 0.4 & 0.6 & 0.6 & 3 & 2 & 4 & 1 & 0 & 0 & 1 & 1 & $498.701,6$ \\
\hline 0.4 & 0.4 & 0.8 & 0.8 & 3 & 2 & 4 & 1 & 0 & 0 & 1 & 1 & $477.358,7$ \\
\hline
\end{tabular}

\section{Conclusion}

The Model [SITM] has integrated batch production scheduling and maintenance scheduling for single item processed on flow shop with two machines to minimize the total cost consisting of inventory holding costs, setup cost, maintenance costs and rework cost.

The solution search method for the integrated problem was calculated by relaxing the problem into two step optimization, i. e., to determine the batch production schedule for both machines and to determine the expected number of corrective maintenance and the expected number of non-conforming parts obtained from determining the production schedule for both machines. Steps in the Algorithm [SITM] show a trade off in production and maintenance cost. Algorithm [SITM] gives solution of the problem 
as minimization of a set of the best total cost for all possible combinations of the number of production run for both machines.

\section{Acknowledgments}

The authors wish to thank the editors and the referees for their suggestions and corrections. This research is funded by the grant of applied products scheme with contract number 039A/VR.RTT/VI/2017 by Department of Research and High Education Republic of Indonesia.

\section{References}

Ben-Daya, M., \& Noman, S. A. (2006). Lot sizing, preventive maintenance, and warranty decisions for imperfect production systems. Journal of Quality in Maintenance Engineering, 12(1), 68-80.

Berrichi, A., Amodeo, L., Yalaoui, F., Châtelet, E., \& Mezghiche, M. (2009). Bi-objective optimization algorithms for joint production and maintenance scheduling: application to the parallel machine problem. Journal of Intelligent Manufacturing, 20(4), 389.

Chelbi, A., Rezg, N., \& Radhoui, M. (2008). Simultaneous determination of production lot size and preventive maintenance schedule for unreliable production system. Journal of Quality in Maintenance Engineering, 14(2), 161-176.

Chiu, Y., Lin, H., Wu, M., \& Chiu, S. (2018). Alternative fabrication scheme to study effects of rework of nonconforming products and delayed differentiation on a multiproduct supply-chain system. International Journal of Industrial Engineering Computations, 9(2), 235-248.

El-Ferik, S., \& Ben-Daya, M. (2010). Integrated production maintenance model under imperfect agebased maintenance policy and non-negligible maintenance times. Asia-Pacific Journal of Operational Research, 27(04), 539-558.

Fitouhi, M. C., \& Nourelfath, M. (2012). Integrating noncyclical preventive maintenance scheduling and production planning for a single machine. International Journal of Production Economics, 136(2), 344-351.

Halim, A. H., \& Ohta, H. (1994). Batch-scheduling problems to minimize inventory cost in the shop with both receiving and delivery just-in-times. International Journal of Production Economics, 33(1-3), 185-194.

Lee, H. L., \& Rosenblatt, M. J. (1987). Simultaneous determination of production cycle and inspection schedules in a production system. Management science, 33(9), 1125-1136.

Lin, L., \& Hou, K. (2005). EMQ model with maintenance actions for deteriorating production system. International Journal of Information and Management Sciences, 16(1), 53.

Mo, S., Zeng, J., \& Xu, W. (2017). A new warranty policy based on a buyer's preventive maintenance investment. Computers \& Industrial Engineering, 111, 433-444.

Moradi, E., Ghomi, S. F., \& Zandieh, M. (2011). Bi-objective optimization research on integrated fixed time interval preventive maintenance and production for scheduling flexible job-shop problem. Expert systems with applications, 38(6), 7169-7178.

Murthy, D. N. P., \& Jiang, R. (2008). Maintenance: decision models for management (Vol. 1, pp. 1-305). Science Press.

Prasetyaningsih, E., Suprayogi, S., Samadhi, T. A., \& Halim, A. H. (2017). Production and Delivery Batch Scheduling with Multiple Due Dates to Minimize Total Cost. Journal of Engineering and Technological Sciences, 49(1), 16-36.

Suliman, S. M., \& Jawad, S. H. (2012). Optimization of preventive maintenance schedule and production lot size. International Journal of Production Economics, 137(1), 19-28.

Tseng, S. T. (1996). Optimal preventive maintenance policy for deteriorating production systems. IIE transactions, 28(8), 687-694.

Wang, C. H., \& Sheu, S. H. (2001). Simultaneous determination of the optimal production-inventory and product inspection policies for a deteriorating production system. Computers \& Operations Research, 28(11), 1093-1110. 
Winston, W. L., \& Goldberg, J. B. (2004). Operations research: applications and algorithms (Vol. 3). Belmont: Thomson Brooks/Cole.

Yusriski, R., Sukoyo, S., Samadhi, T. M. A. A., \& Halim, A. (2015). Integer batch scheduling problems for a single-machine with simultaneous effect of learning and forgetting to minimize total actual flow time. International Journal of Industrial Engineering Computations, 6(3), 365-378.

Zahedi, Z., Samadhi, T., Suprayogi, S., \& Halim, A. (2016). Integrated batch production and maintenance scheduling for multiple items processed on a deteriorating machine to minimize total production and maintenance costs with due date constraint. International Journal of Industrial Engineering Computations, 7(2), 229-244.

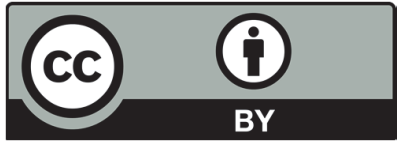

(C) 2019 by the authors; licensee Growing Science, Canada. This is an open access article distributed under the terms and conditions of the Creative Commons Attribution (CCBY) license (http://creativecommons.org/licenses/by/4.0/). 